\title{
Naked Women of North America
}

Naked women in broad daylight, or almost naked, naked in theory. They are intrepid like the creatures of the Galapagos Islands; they are manifold, and interesting. One finds them at the outskirts of a party, behind the list of numerals printed on a sail. They pile up, the naked women. Naked women with markings, naked women that refuse to negotiate, a long discussion of naked women once took place amongst a distinguished panel of underpaid naked women, culminating in a large group of naked women eating dinner in a parking lot. Naked women, ahead of their time. Naked women appear in agate type at the bottom of a contract. In an ideal world, naked women with fine print and limitless potential. Yes, in a coal mine, naked women. Rich veins of naked women struck as loosely-translated slang. Sanskrit slang. Anne Carson: maleness and sound, maleness and lists. Anne Frank: the private jokes of a whole family of naked women hiding from the authorities of death. There are myths, non-myths. Naked women going bananas over some unknown situation, for example. This never occurred.

Except once. Nor did the naked women who were given three wishes by a fantastical genie exist, only to end up contaminating the water table. Naked women, goats. Naked women and an armful of statues. One can joke about them and history won't exist, I enjoy statues, and so do the naked women

in my life. Very serious naked women, humorless, plagiarizing an amusing work of American poetry: these are the women that I'm talking about. They fly around the room at all angles, they're found in every level of government. These naked women have complex ideas.

Naked women conduct, naked women ensue. A friend of mine, Dr. Phillips, describes the way naked women are known to have hidden meanings, memorize flash cards, enforce wild policies. He is especially interested in the miles per hour of naked women. He captured fifty psychedelic naked women that were ready for action and cast them, instead, in an action film. He advertised naked women in bulk; he spent billions promoting the naked women 
that give you total enlightenment and everlasting peace, he issued coupons for naked-woman lessons. Good old-fashioned naked women.

Naked women are also found in special-interest magazines. Naked women that know karate, ornery naked women from Oklahoma or Texas, socially-aware naked women. Naked women just hanging out, naked women that make you feel stupid. Naked women that descended from single-celled organisms over millennia, or very quiet naked women holding light bulbs, British naked women, naked women brought in from across Europe. It's more or less sexual. These women that I'm talking about are naked: they have dead teeth. Some of them are barren naked women, women screaming that their babies need blood to survive. All the damn teenagers and their naked women. The most appealing naked women covered in confetti, stuck to their bodies, the one particular naked woman

multiplied by however many are needed. Look. Some naked women nowinstant naked women, naked women collapsing under the weight of their genius, goddamn naked women on the goddamn internet, naked women and God, naked women saying "let's get the hell out of here, this is boring," the plural and singular nature of naked women, naked women carrying the air like it could break, black holes, many, naked singularities, time-travel, naked women at sea, naked women whose shapes are fed by a natural aquifer, calling attention to themselves, naked women, familiar naked women, animals, anonymous naked women who are now well-known, familiar naked women, inventing the steam engine, naked women, at the worst possible time. 